\title{
Understanding and interpreting the drivers of the Knowledge Economy
}

\author{
Mohan R. Gurubatham \\ International Business School, University Technology Malaysia, Level 2, IBS Building, Jalan \\ Semarak, 54100 Kuala Lumpur, Malaysia.
}

mohang@streamyx.com

Abstract: The Knowledge Economy (K-economy) is much heralded as enabling the death of distance, the opportunities and promise of human capital development via life long learning and e- learning, the development of learning communities and knowledge enrichment of communities through community portals, to mention a few of the implications. It is certainly quite obvious that the K-economy is much more, than just technological software or hardware. The enablement of knowledge acquisition and utilisation, so that information can be effectively, efficiently and meaningfully transformed into wisdom, is examined along two fronts:

Which drivers induce the diffusion and adoption of ICT globally? What attitudes and competencies facilitate or impede the adoption process? The notion of cognitive literacy will be examined in this context.

What are the needs and wants of knowledge societies that can be facilitated as design features for learning by understanding the subtleties of the dimensions of culture both from national and organisational perspectives? An ecotextural paradigm is used to frame the discussion of the integral role of enabling technologies, in learning, personal and cultural enrichment. It is envisaged that the role of both affective and cognitive dimensions will be validated in wisdom attainment as the fulfilment of the Knowledge Society.

Key words: cognitive literacy, knowledge economy drivers, schema, transcend, value adds 


\section{KNOWLEDGE ECONOMY'S TECHNOLOGICAL DRIVERS}

So what is exactly driving the knowledge economy? The answer first appears to be an interaction of the three technological drivers of the knowledge economy. These are specifically:

1. Moore's Law - the maximum power of a processing microchip at a given price doubles every 18 months. So What? Computers become faster while the price for a given level of computing halves.

2. Gilders Law - the total bandwidth of communication systems will triple every 12 months. So what? There is an approximately $40 \%$ decline in the unit cost of the net

3. Metcalf's Law - the value of a network is proportional to the square of the number of nodes. So what? With network growth, the value being of connected grows exponentially and costs per user holds constant and ultimately falls.

\section{Induction and diffusion of the drivers}

As computing power practically doubles, affordability becomes a more salient albeit promising dimension in providing access to the technology. Hardware adoption rates may seem staggered along the specific types of computing hardware enabled by the promise of Moore's Law until the end of this decade.

\section{Business Drivers behind ICT adoption}

Next, we outline the major business developments of the technological drivers of the knowledge economy discussed thus far. Behind all of these drivers is the explosion of information and communication enabled by the ubiquity of ICT.

\section{Guiding Principle 1: The growth of international business where globalisation is inevitable.}

- Perfect competition is increasingly real. Consumers are price savvy for any product anywhere by the 'death of distance'. There is demand to find new markets overseas. New markets are opened up anywhere and anytime. 24/7 customer service cycles such as call centres in India are 
now commonplace by business to consumer electronic commerce. With the advent of direct broadcast satellites and digital service lines, consumers are increasingly cognisant of consumption and lifestyles of their peers elsewhere. Expectations are engendered for price, quality and service.

- There is demand for quality management systems from overseas markets with higher customer expectations of value added. There is required agility to respond to evolving customer niches. For example, Southwest airlines business success has inspired similar low cost strategies in the EC by Ryan Air and even South East Asia by the emergence of Malaysian -based Air Asia.

- The deregulation of markets for entree by international firms into domestic markets have seen restructuring, reengineering and right sizing in the financial services and telecommunications industry. Other industries are not immune. There is increasing competition for presently protected monopolies. China after its WTO entree dramatically challenges other counties on cost and quality, or to climb the value chain ahead of it. Within China alone, expectations of consumers are being raised. China's Internet penetration rate is $5 \%$ or 56.6 million (A.C. Nielsen 2002). India while far lower than China in FDI is increasingly capable of competing in branded services and Information Technology Enabled Services (ITES). In terms of outsourcing these surging, not emerging economies represent competitive lower cost advantages.

Guiding Principle 2: There is an evolution from 'hard' value to 'soft' value where knowledge holds a disproportionate premium as an asset. Knowledge is essentially a mental product.

- The value of intellectual capital is greater than raw materials, manufacturing assembly and infrastructure alone. Nations have to climb up the value chain in of higher value added in technological innovation and creativity.

- Previously Neo Classical economics only recognized 2 factors of production: labour + capital.

- Now, New Growth Theory includes technology and has basis in Knowledge as intrinsic to the economic growth (Romer 1986; 1990). New Growth predicts technical platform effects and non-rivalry, that can lead to increasing returns on technology investment such as in 'open source' advocacy. 
- New technology multiple potential effects for further platforms, is not one-off. Promise of diminishing returns is possible. Technology thus can raise Return on Investment. So developed economies can sustain growth.

- By traditional economic predictions there are diminishing returns. Developing economies even with unlimited labour cannot attain growth.

- Even in sectors such as manufacturing and government, ICT has ramifications. Just-In-Time-Information (JITI) informs the right person at the right time; from here knowledge workers must transform data into knowledge and application. Web-enabled business transactions drive speed, cost and partnering expectations. Scanning best practices, relearning and reinventing if necessary to stay ahead competitively must enliven the continuous and discontinuous process of shortening lead times. From performance management in well run airlines to global consulting firms as well 'old economy' manufacturing, knowledge management has caught on as in the case of Buckman Labs in the USA and Cemex in Mexico.

\section{Guiding Principle 3: Soft knowledge can transcend 'hard' physical boundaries; ICT as process and not just infrastructure, enables the ubiquity of information.}

- The death of distance is ubiquitous. In China, the proportion of internet users in a city is not determined by its size and stage of development. Chinese urban dwellers see it positively, as a virtual meeting place albeit in China only (Guo Liang 2004).

- The death of distance advantage is leveraged by the firm that has the greatest value-addition, the lowest 'weight' i.e., an intangible factor that transcends the 'weight' of industrial products such as from manufacturing. An example is software or solutions such as by INFOSYS, an Indian firm which is now a global brand name performing in markets such as the United States and Japan, and a quality performing stock in the NASDAQ, USA.

- Human capital investments are mandated to leverage the discontinuous improvements in Information Technology Enabled services (ITES). Relatively 'poor' countries such as India have surprised the world with their prowess in ITES. Enabled by the emergence of high bandwidth telecommunications networks, offshore business processing has indeed proved not just very viable, but also profitable. The range of Indian ITES services include the back-office processing of financial services, data mining and call-centres. Indeed a study by NASSCOM-McKinsey (2002) 
Economy

has predicted at least $77-80$ billion USD worth of revenue by 2008 in these services.

- ICT raises the profile of brands as perceptual assets. Brands are schema or mental short hands. Brands are critical because they reinforce consumers' trust. Brands transcend the functional attributes of their products but remain integrated within an ecosphere that reinforces consumer lifestyles and belief systems e.g., SKALI.net in Malaysia.

These drivers are related and fluidly interact to create a dynamic landscape of trends and events that have both intended and unintended consequences. Results of these drivers necessitate human capital investment to enhance the competitiveness of the workforce. ICT is thus the enabler. Next we look at the role of ICT in human capital development.

\section{HUMAN CAPITAL DEVELOPMENT AND ICT}

Firstly, factors that promote successful ICT adoption in organisations are:

- Strategically mandated organisational learning. Senior management must sponsor and relentlessly communicate that learning by trying out is alright. Emergent learning drives emergent strategies that better shape organisational resilience. Heuristics as opposed to algorithmic planning is more suitable for turbulent environments where organisations need to thrive or survive in uncertainty. Such is the environment that we currently face.

- Communication is part-and-parcel of the process of knowledge sharing. Knowledge management is doomed for failure, if recognition and reward systems are not in place for populating and accessing databases.

- The practical application of this value adding chain of information literacy in the management of the cultural environment demands not only empowerment, but managed responsibility. In the management of cognitive development, 'mindfulness' (Langer, 1997), and the sustenance of mindfulness (Senge, 1999), support mechanisms must be in place both formally and informally.

- Alignment of work roles to mission critical competencies so that career paths are defined against organisational goals. This signals that organisations are viable and desire longevity through adaptation beyond a short-lived project mindset.

- A transparent process view of value addition across work roles that diminishes silo thinking. 
- Organisations that stress functional competencies still structure most departmental units as 'silos'. This is common in developing countries. To the extent that silos dominate, an overall and transparent value-chain 'process' mindset that transcends 'passing-the-buck' and finger-pointing of individual egos and departments is unfortunately dissipated or lost even with all the e-enablement. What are required are broad comprehension, sharp focus and commitment to teamwork imbued with a lively sustained sense of organisational mission and alignment.

- Active sponsorship, either morally or financially, for lifelong learning that enriches both work and play so that good performers bind to the organisation.

- Understanding that knowledge work involves the active manipulation of symbols to yield knowledge and ultimately wisdom. This is a process of human development that requires education, coaching and mentoring. With the adoption of ICT, the technology enhances this with accessibility, speed, reliability and scalability of data.

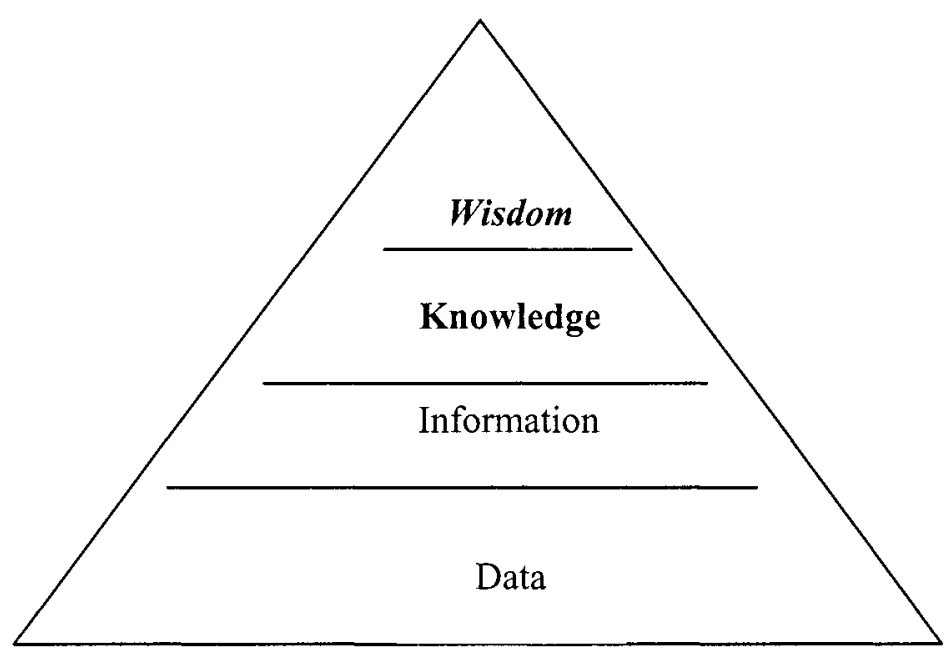

Figure 1. The Cognitive Literacy Chain

\section{THE COGNITIVE LITERACY VALUE CHAIN}

In the hierarchy of knowledge, data represent the lowest level of information value. The distinctive competency at this level is accuracy and speed. This level should be automated by information technology requiring 
little or no vigilance by human operators. In the 21 st century, this level of the chain has little competitive advantage.

Next, the level of information represents more active information processing in interpreting data. Typical activities at this level for example include quickly recognizing critical quality parameters such as in statistical process control, inputting unique customer data in Customer Relationship Applications (CRM) while on-line, and recognizing key or salient customer information in call-centre tasks. These activities call for competencies in perceptual abilities.

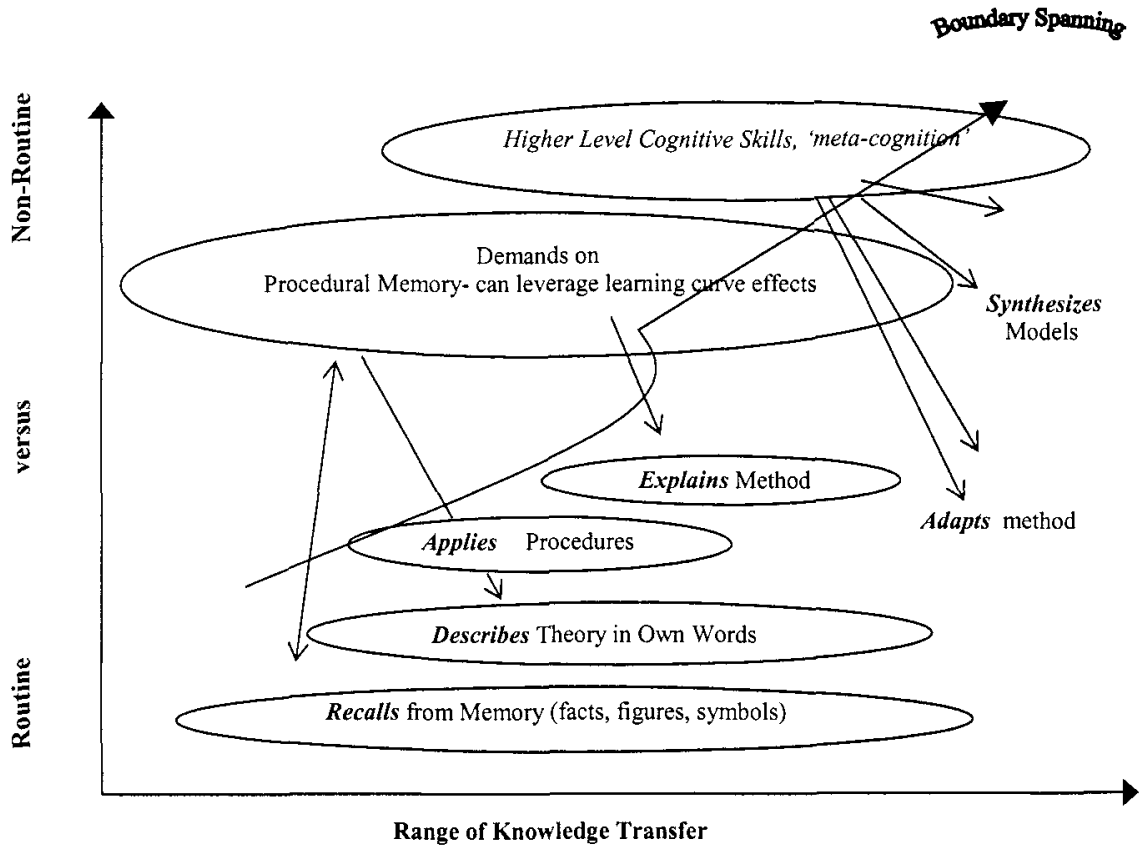

Figure 2. The range of knowledge transfer

Knowledge is higher-level cognitive activity, such as concept attainment, problem solving and innovation. Examples of such activity include coding (programming) software, applications, trouble-shooting, manpower and succession planning. Most of the routine administrative and management competencies that involve discrimination and judgment enabled by computer applications, such as Human Resource Information Systems (HRIS) or Enterprise Resource Planning systems (ERP), may be categorized at this level. Other examples of value-added thinking include the ability to 
extrapolate and interpolate data in market trends, even in the face of 'missing data or information' - breakthrough thinking is often experienced as this.

The uppermost level of the cognitive literacy is wisdom which is deeper and wider. Wisdom is essentially an evaluative and integrative mode of thinking that can subsume the lower cognitive levels of thinking. The ability to integrate and evaluate requires use of the 'lower' levels of mental activity such as perception and cognition, but more critically, its success rests on the ability to yield insight that derives from more than the sum-of-parts of data. This process, which has been described in hierarchies such as Bloom's Taxonomy, involves affective and ethical dimensions of human judgment. Examples include the ability to integrate and evaluate simulations and perform strategic scenario planning such as in market research involving data mining, multidimensional scaling, organisational modelling and so on. Often this value is driven by well-developed social cognition schema and by what is commonly dubbed as intuition. Ethical judgments predicated upon higher levels of moral development can safeguard against the abuse of the access of information. Cultural values and assumptions can subtly and powerfully influence evaluations. Wider and deeper cognisance must encompass varieties of stakeholders.

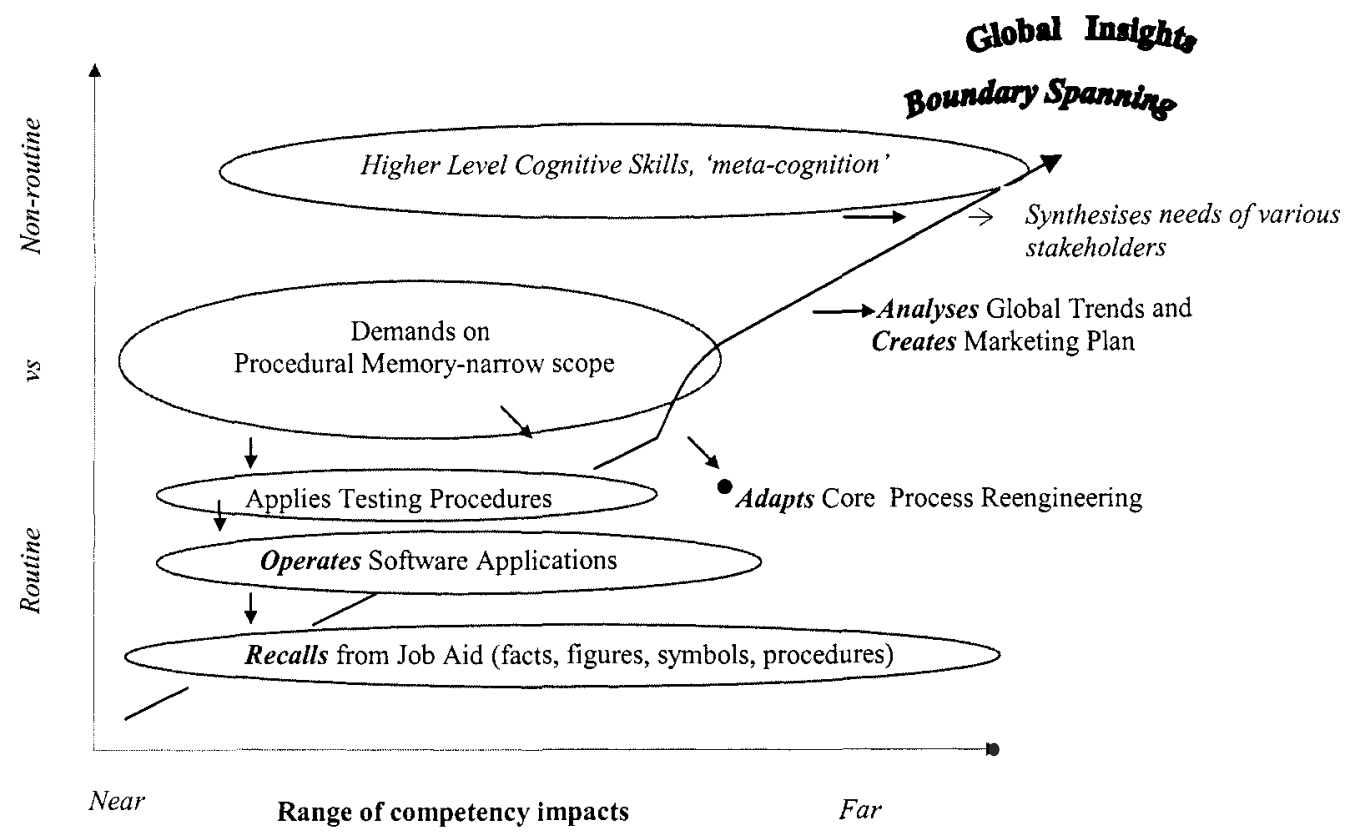

Figure 3. The range of competency impacts 
Economy

If knowledge transcends physical boundaries, deeper knowledge transcends domains of function but capture overall process. Such knowledge is essentially higher value added or Key Value Added (KVA) i.e., how long does an average person require to learn a process as embedded knowledge. (Kannan \&Akhilesh, 2002).

Learning that nudges higher value added thinking is dubbed 'far transfer' (Salomon and Perkins 1989). Such learning is insightful, and often based upon deep principles that transcend context or domain (Figure 2.). Its range of competency impacts transcends organisational boundaries (Figure 3.). Learning strategies that induce these include meta-cognitive, i.e. 'high road' strategies such as reflection, analogising by cases and boundary pushing, Socratic prompting, introspecting assumptions and values. Techniques that expand the conscious thinking mind such as Transcendental Meditation ${ }^{\mathrm{TM}}$, indicate increased operationally defined wisdom and enliven the whole brain. Well-controlled and longitudinal studies have found that TM practice enhances a wide range of functions spanning the entire cognitive literacy chain, including developing shorter response latencies in discrimination tasks, increased field independence, increased flexibility of perception and improved verbal problem solving, increased and creativity, and increased fluid and culture fair intelligence. For a thorough review of published studies, see Alexander C. N. (1993).

Next, we look at the role of culture in cognition and ICT.

\section{LEARNING ICT AND CULTURE}

Schemas are mental structures that guide human information processing. They are the basis of norms, parameters and expectations. Schemas are automated in long term human memory over time as 'scaffolds' that drive the top-down assimilation of information and file data into categories. Culture is schematised over long periods of time (Gurubatham 2001). Cultural schemas act as 'notional guidance systems'-'scripts' that guide behaviour in cultural settings, and can stubbornly and subtly influence higher-level thinking.

Cultural scripts may represent obstacles that impede or facilitate learning and successful adaptation to globalisation. Cultural adaptation typically does not commensurate with economic growth. Unbundling automated cultural schema is inherently stressful (Gurubatham 2001) What is needed is a way to preserve the ecological diversity of culture, harness it and transcend it for cognition of deeper, universally shared values and laws. An analysis of 
the major cultural dimensions will help to structure ICT interventions effectively.

The Dimensions of Hofstede's Ecological Factor Analysis (1980; 1991):

- Power Distance (PD) indicates perceptions of distribution of power in society. In organisations, High PD indicates hierarchical relationships, status effects, top-down communication and authority-compliant behaviour. Norms, rules and work cultures are top-down, and organisational members are socialised into this. Examples are Asian, African and Middle Eastern and 'Latin' societies.

- Low PD indicates flat organisational structures equality status, informality and horizontal flow of communications. Examples are largely western nations and organisations.

- Collectivism indicates the degree of group orientation from individualistic to high collectivist. Westerners by and large are individualistic compared to Asian, African and Middle Eastern and 'Latin' societies. Note a related concept of High and Low Context by Hall (1976). High Context (HC) is characterised by relationships, importance of non-verbal communications, warmth, and polychronic in time orientation i.e., multi-track and non-linear time perception. Low context (western-industrialised) is more digital' and emphasises verbal communication, rigid task orientation and punctuality. High HC may also be characterised by a natural alignment of the transcendent Self with the ecosystem and the cosmos (Gurubaham 2001). Intuition here is refined affect and may underpin wider and deeper judgement i.e., wisdom. Indeed, affect may be more archetypal and bypass typically 'western' cognitive activity (Zajonc 1980).

- Masculinity versus femininity indicates a continuum of separating gender role definitions. Masculine cultures prefer rigid gender roles and are stress-confrontative and stress-achieving. Feminine cultures stress nurturance. Japan, Austria, the USA and Arab countries score high in masculinity, whereas the Scandinavian counties score low.

- Uncertainty Avoidance (UA) is the degree of risk aversion where high UA avoids risk and low accepts and even welcomes it. High UA cultures tend to be expressive, desire structure, simplicity and formality, are more likely to resist change and tend to be more proactive than ad hoc. Most Asian countries are high UA except Hong Kong which scores the lowest globally. Low UA favours informality and relaxed business arrangements, lives day-to-day with loyalty not being paramount.

- Long Time Orientation is simply a culture's reverence for patience, social trust and unequal social relations. Originally a Confucian concept, but is somewhat confounded in globalisation as Chinese societies are rapidly modernising today. Even in smaller Chinese cities, 


\section{Economy}

there is a major perception among internet users who see it as a tool for freer political discussion and view its content with social trust (Guo Liang 2003), counterbalanced by a wider social need to control it.

\section{CONCLUSION AND ECOTEXTURE}

Since culture evolves slowly and is stubborn a wise guiding principle is to work with it rather than change it. Accept it as part of the ecotexture.

\section{ICT Design Features by Non Western Cultural-Considerations}

- Higher Power Distance (PD) will naturally prefer a relatively higher degree of information structure than lower PD. Control and access issues are very important with centralised power structures. Mental models or schema may favour hierarchical relations.

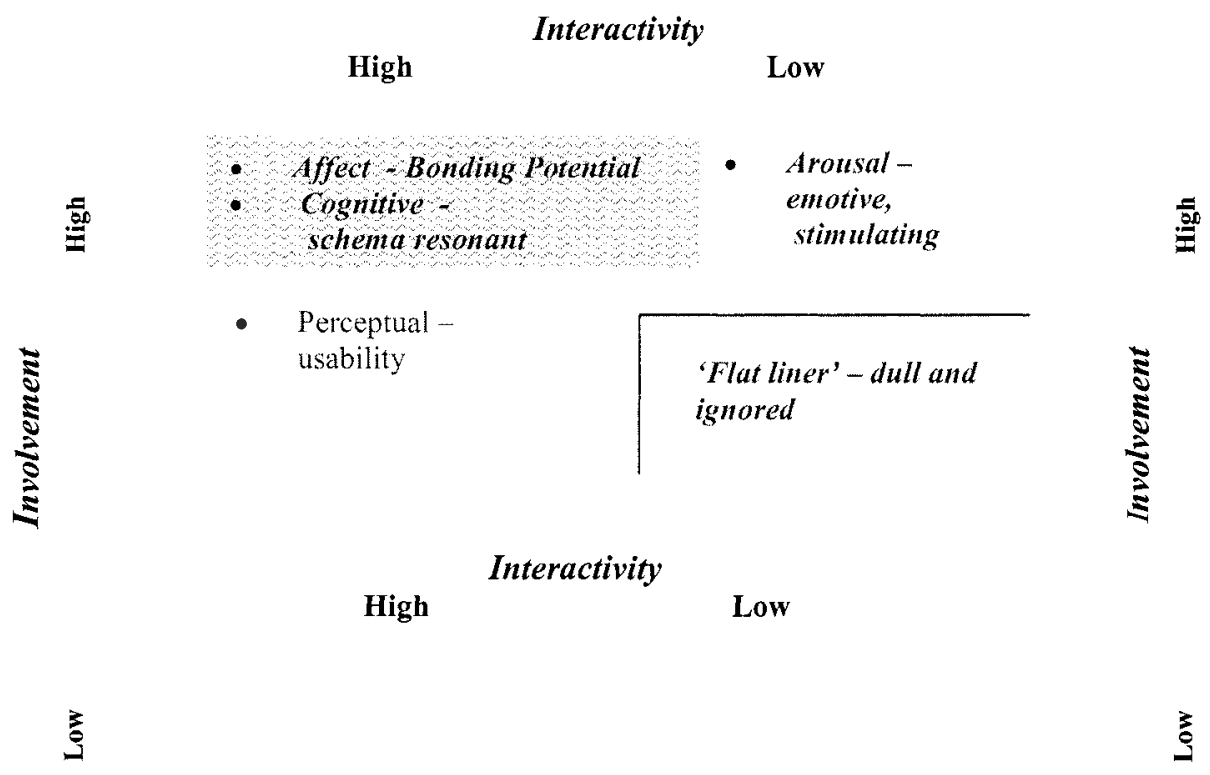

Figure 4. K-economy e-media process

Further, high PD may inhibit participative management that solicits inputs from workers by their formal hierarchies. Also favours official insignia, 
logos, and content certification. Formal status effects are active that may inhibit for example a professor's acceptance in chat rooms.

- In High Context (HC) collectivist e-learning and knowledge management, courtesy, personal acknowledgment, ritual and relationships can be infused into the content to counterbalance the formality of power distance. High context cultures are naturally coherent and are informal in communications. ICT should complement this trait. Affect in $\mathrm{HC}$ is enlivened this way. Some of the elements of polychronicity may be exploited and synergised over time to accommodate a higher degree of task orientation for multitasking such as in call centres, utilizing on-line performance support while attending to customers.

- Masculinity and femininity - feminine cultures may be more comfortable with content ambiguity in gender roles. Masculine content may be biased towards task, mastery, sport, and utilitarian features.

- Long Time Orientation content - content, interactivity and involvement must focus on personal relationships as trusted information sources, patience in achieving results - usually social goals, and pragmatic value (Guo Liang 2003).

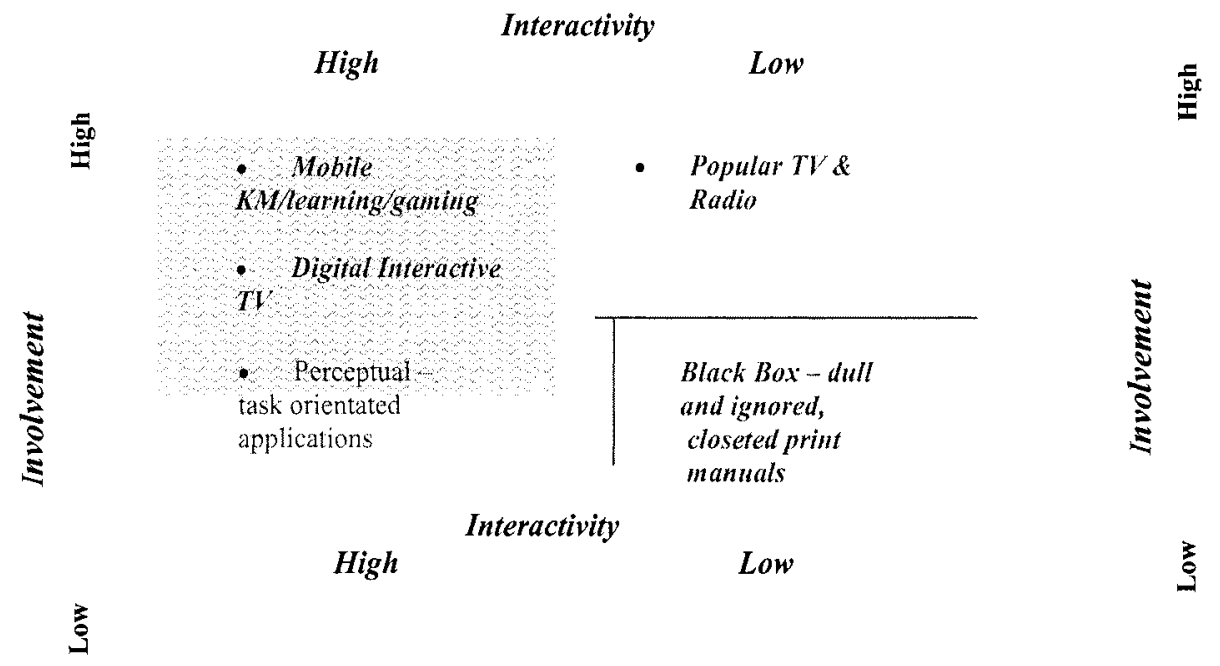

Figure 5. K-economy media genre

- High Uncertainty Avoidance (UA) may also inhibit 'discovery' (inductive) learning and needs prompts and debriefs until confidence is acquired. 'Advance organisers' (concept maps), visual aids or metaphorical, culturally endeared phrases may be used to provide $\mathrm{HC}$ 
and UA learners with navigation for complex content. Learner control may be initially inhibited and requires active coaching in the initial stages of e-learning. High UA may also inhibit populating databases in knowledge management. Counterbalance by enlivening the high context of teamwork, sharing and interpreting information. Level of choice and amount of data should be low. Keep out superfluous links. A help system is better if it is task driven rather than content driven.

The far transfer of knowledge establishes a guiding principle that ICT must strive for. Design features must include interactivity (usability) and especially deeper involvement (psychological bonding inherent in the culture) as seen in examples in Figures 4 and 5 .

The use of multiple scenario simulation outcomes in content that is culture-varied and rich, with inductive principles complemented by coaching, can nudge the 'far transfer' of key principles that transcends context, yet appreciates diversity and engenders wisdom.

New 'wisdom technologies' such as Transcendental Meditation programs are "Natural Law' based. TM research indicates attainment of psychological stability even in the face of stressful environmental stimuli (Orme-Johnson 1973) so that individuals and groups enjoy both progress and their cultural heritage. In this technique, individuals practically experience their Self as the Unified Field underlying all cultural diversity and change (Chandler et al. 2004; Broome et al. 2004).

\section{BIOGRAPHY}

Mohan Raj Gurubatham is interested in the cultural and cognitive bases of learning and strategy in advanced Asian countries especially with pressures of globalisation in the knowledge economy. $\mathrm{He}$ is currently integrating the role of intangible factors in ICT within organic 'eco-field' frameworks that will shape practical consequences.

\section{REFERENCES}

Alexander C N (1993). Transcendental meditation. In Corsini, R J (Ed.), Encyclopedia of Psychology, $\left(2^{\text {nd }}\right.$ ed.), New York, Wiley Interscience. 
Broome, R., Orme-Johnson, D. W., \& Schmidt-Wilk. J. (in press) Worksite stress reduction through the Transcendental Meditation program. Journal of Social Behavior and Personality.

Chandler, H. M., Alexander, C. N., \& Heaton, D. P. (in press). Transcendental Meditation and postconventional self-development: A 10-year longitudinal study. Journal of Social Behavior and Personality.

Guo Liang (2003) The Cass Internet Report 2003: Surveying Internet Usage and Impact in Twelve Chinese Cities, Chinese Academy of Sciences, Beijing.

Gurubatham, M. R. (2001) Maximising Human Intelligence Deployment in East Asia-The $6^{\text {th }}$ Generation Project, Palgrave, London.

Hofstede G. (1980) Culture's Consequences: International Differences in Work-related values. Beverly Hills: Sage

Hofstede, G. (1991). Cultures and Organisations: software of the mind. London: McGrawHill.

Hall ET (1976) Beyond Culture. New York, Anchor Books.

Kannan, G. and Akhilesh K.B. (2002). Human capital knowledge value added: A case study in infotech. Journal of Intellectual Capital, Bradford. Vol.3, Issue 2: pp. 167-180.

Langer Ellen J. (1997) The Power of Mindful Learning. New York : Addison-Wesley Publishing Company Inc.

Orme-Johnson, D.W. (1973). Autonomic stability and Transcendental Meditation. Psychosomatic Medicine, 35, pp. 341-349.

Romer, Paul M., (1986) Increasing Returns and Long-Run Growth, Journal of Political Economy 94(5), pp.1002-37.

Romer, Paul M., (1990) Endogenous Technological Change. Journal of Political Economy 98(5), pp. 71-102.

Salomon,G., \& D. P. Perkins (1989) Educational Psychologist, 24(2), pp. 113-142.

Schmidt-Wilk, J. (2000). Consciousness-based management development: Case studies of international top management teams. Journal of Transnational Management Development, 5 (3), pp. 61-85.

Senge P, George R \& Bryan S (1999) The Dance of Change; The Challenges of Sustaining Momentum in Learning Organizations. New York: Doubleday.

Zajonc, R (1980) Thinking and Feeling: Preferences Need No Inferences. American Psychologist 35, pp. 151- 175. 